\title{
Comparison of pathological characteristics between self- detected and screen-detected invasive breast cancers in Chinese women: a retrospective study
}

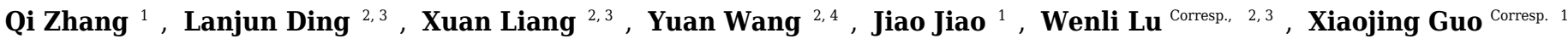 \\ 1 Department of Breast Pathology and Lab, Tianjin Medical University Cancer Institute and Hospital, Tianjin, China \\ 2 Department of Epidemiology and Health Statistics, Tianjin Medical University, Tianjin, China \\ 3 Collaborative Innovation Center of Chronic disease prevention and control, Tianjin Medical University, Tianjin, China \\ ${ }^{4}$ Collaborative Innovation Center of Chronic Disease Prevention and Control, Tianjin Medical University, Tianjin, China \\ Corresponding Authors: Wenli Lu, Xiaojing Guo \\ Email address: luwenli@tmu.edu.cn, guoxiaojing@tjmuch.com
}

Background: In China, there is insufficient evidence to support that screening programs can detect breast cancer earlier and improve outcomes compared with patient self-reporting. Therefore, we compared the pathological characteristics at diagnosis between self-detected and screen-detected cases of invasive breast cancer at our institution and determined whether these characteristics were different after the program's introduction (versus [vs] prior to).

Methods: Three databases were selected (breast cancer diagnosed in 1995-2000, 2010, and 2015), which provided a total of 3,014 female patients with invasive breast cancer. The cases were divided into self-detected and screen-detected group. The pathological characteristics were compared between the two groups and multiple imputation and complete randomized imputation were used to deal with missing data.

Results: Compared with patient self-reporting, screening was associated with the following factors: a higher percentage of stage T1 tumors (75.0\% vs $17.1 \%, \mathrm{P}=0.109$ in $1995-2000 ; 66.7 \%$ vs $40.4 \%, \mathrm{P}<$ 0.001 in 2010; $67.8 \%$ vs $35.7 \%, P<0.001$ in 2015); a higher percentage of tumors with stage N0 lymph node status (67.3\% vs 48.4\%, $\mathrm{P}=0.007$ in 2010); and a higher percentage of histologic grade I tumors (22.9\% vs $13.9 \%, P=0.017$ in 2010$)$.

Conclusions: Screen-detected breast cancer was associated with a greater number of favorable pathological characteristics. However, although screening had a beneficial role in early detection in China, we found fewer patients were detected by screening in this study compared with those in Western and Asian developed countries. 
1 Comparison of pathological characteristics between self-detected and screen-detected invasive

2 breast cancers in Chinese women: a retrospective study

3 Qi Zhang, M.S. ${ }^{1,4}$, Lanjun Ding, M.S..-4, Xuan Liang, M.S.,3, Yuan Wang, M.D. ${ }^{2,3}$, Jiao Jiao, M.S. ${ }^{1}$, Wenli Lu,

4 Ph.D. ${ }^{2,3^{*}}$, Xiaojing Guo, Ph.D. ${ }^{{ }^{*}}$

$5{ }^{1}$ Department of Breast Pathology and Lab, Key Laboratory of Breast Cancer of Breast Cancer Prevention and

6 Therapy, National Clinical Research Center of Cancer, Tianjin Medical University Cancer Institute and Hospital,

7 Huanhu Xi Road, Hexi District, Tianjin 300060, China,

$8{ }^{2}$ Department of Epidemiology and Health Statistics, School of Public Health, Tianjin Medical University, 22

9 Qixiangtai Rode, Heping District, Tianjin 300070, China

$10{ }^{3}$ Collaborative Innovation Center of Chronic disease prevention and control, Tianjin Medical University, 22

11 Qixiangtai Rode, Heping District, Tianjin 300070, China

$12{ }^{4}$ These authors contributed equally to this paper

13

$14 *$ Corresponding authors:

15 Xiaojing Guo, M.D., Ph.D., Professor, Department of Breast Pathology and Lab, National Clinical Research Center

16 of Cancer, Tianjin Medical University Cancer Institute and Hospital, Huanhu Xi Road, Hexi District, Tianjin,

17 300060, China. Fax \& Tel: 86-22-23340123(6119); ORCID: 0000-0003-3138-7706; E-mail:

18 guoxiaojing@tjmuch.com

19 Wenli Lu, M.D., Ph.D., Professor, Department of Epidemiology and Health Statistics, School of Publish Health,

20 Collaborative Innovation Centre of Chronic disease prevention and control, Tianjin Medical University, 22

21 Qixiangtai Rode, Heping District, Tianjin, 300070, China. Fax: 86-22-83336606; Tel: 86-22-83336619; ORCID:

22 0000-0003-2894-7506; E-mail:luwenli@tmu.edu.cn 


\section{Abstract}

24 Background: In China, there is insufficient evidence to support that screening programs can

25 detect breast cancer earlier and improve outcomes compared with patient self-reporting.

26 Therefore, we compared the pathological characteristics at diagnosis between self-detected and

27 screen-detected cases of invasive breast cancer at our institution and determined whether these

28 characteristics were different after the program's introduction (versus [vs] prior to).

29 Methods: Three databases were selected (breast cancer diagnosed in 1995-2000, 2010, and 30 2015), which provided a total of 3,014 female patients with invasive breast cancer. The cases 31 were divided into self-detected and screen-detected group. The pathological characteristics were 32 compared between the two groups and multiple imputation and complete randomized imputation 33 were used to deal with missing data.

34 Results: Compared with patient self-reporting, screening was associated with the following

35 factors: a higher percentage of stage T1 tumors $(75.0 \%$ vs $17.1 \%, \mathrm{P}=0.109$ in $1995-2000 ; 66.7 \%$

36 vs $40.4 \%, \mathrm{P}<0.001$ in $2010 ; 67.8 \%$ vs $35.7 \%, \mathrm{P}<0.001$ in 2015 ); a higher percentage of tumors

37 with stage N0 lymph node status $(67.3 \%$ vs $48.4 \%, \mathrm{P}=0.007$ in 2010$)$; and a higher percentage

38 of histologic grade I tumors $(22.9 \%$ vs $13.9 \%, \mathrm{P}=0.017$ in 2010$)$.

39 Conclusions: Screen-detected breast cancer was associated with a greater number of favorable

40 pathological characteristics. However, although screening had a beneficial role in early detection

41 in China, we found fewer patients were detected by screening in this study compared with those

42 in Western and Asian developed countries. 


\section{Introduction}

Breast cancer has become the major cause of death in Chinese women [1, 2]. According to Chinese urban cancer registries, the overall incidence of breast cancer has increased at a rate of $2 \%-$ $5 \%$ annually, with a peak incidence at an age of approximately 50 years $[3-5,2]$. Early tumor detection, before symptoms appear, could significantly improve survival [6-9].

\section{The National Health and Family Planning Commission of the People's Republic of China} organized a three-year breast cancer screening program for women aged 35 to 69 years between 2009 and 2011, with a second phase of screening launched in 2012 [5]. The first phase of the program screened 1.2 million women and detected 440 cases with early-stage lesions, giving a diagnostic rate of 48.0 per 100,000 women [5]. Concurrently, in 2009, the All-China Women's Federation and the National Health and Family Planning Commission organized a screening program that offered free screening for breast and cervical cancer to women in rural China. As of 2014, about 48.35 million women in rural China had received free tests since the program's inception. The guidelines for breast cancer screening in China, which were first published in 2007 and updated in 2015, recommend women at average risk of breast cancer are encouraged to have mammography combined with clinical breast examination after age 40 years. Even though, there is no national organized screening program [10]. Zhu et al reported the long-term prognosis of breast cancers has been improved during the past 40 years [11]. This article was aimed to observe whether the distribution of pathological characteristics at diagnosis had differed since the introduction of limited screening programs.

Studies worldwide have indicated that screen-detected patients have more favorable survival outcomes compared with the patients with self-discovered breast cancer (i.e., self-detected cancer) [12-14]. Screen-detected cancers tend to be of a smaller size, to have better differentiation, and to be at an earlier stage [15]. In a study carried out in a private hospital in 
67 Hong Kong, patients with screen-detected breast cancer had greater numbers of favorable

68 pathological characteristics than a self-detected group [16]. Therefore, the second aim of this

69 study was to compare the pathological characteristics of the self-detected (symptomatic) and

70 screen-detected (asymptomatic) invasive breast cancer in Tianjin, China.

\section{2. Materials and Methods}

2.1 Information of database and subjects

This was a retrospective cohort study conducted at the Tianjin Medical University Cancer

Institute and Hospital. Since 1995, all cases of breast cancer treated in this hospital have been recorded in a structured database. We identified cases for 1995-2000 (paper documentation),

772010 (half paper and half electronic documentation), and 2015 (electronic documentation), taking care to exclude those cases with ductal carcinoma in situ and bilateral breast cancer. The study was approved by the Ethics Committee in Tianjin Medical University Cancer Institute and 80 Hospital.

\subsection{Data extraction}

Clinical histories and pathological characteristics were obtained from the three databases by two authors individually (Zhang Q. and Ding L.), including the age of patients at initial diagnosis

84 and the cancer detection method. Different records between authors were re-checked. 85 Pathological characteristics included tumor size staging and lymph node staging and histologic 86 grade based, respectively, on the tumor-node-metastasis classification system of the American 87 Joint Committee on Cancer [17] and the World Health Organization classification of tumors [18]. 2.3 Methods of detection

Cases were divided into two groups, based on method of detection: a self-detected group and 90 a screen-detected group. Patients in the screen-detected group were primarily screened by 
91 population-based or opportunistic screening with mammography, ultrasound, or clinical breast

92 examination. Patients in the self-detected group were defined as those with obvious clinical

93 symptoms at presentation, including nipple discharge, pain, a palpable axillary lump, a palpable

94 breast lump, or a combination of those symptoms.

952.4 Statistical analysis

96 Descriptive statistics were used to show the demographic and pathological characteristics of 97 the patients. Pearson's chi-square or Fisher's exact test was used to analyze categorical variables, 98 and the Mann-Whitney U test was used to analyze ordinal variables. Multinomial logistic 99 regression analyses were used to analyze associations between method of detection and 100 pathological characteristics. The tumor size (T1, T2 and T3-4), node lymph stage (N0, N1 and 101 N2-3) and histologic grade (I, II and III) were treated as the outcome variables. The category 102 "T1", "N0" and "I" was used as the reference category in tumor size model, node lymph stage 103 model and histologic grade model respectively. The variable "age" was divided into four 104 categories: cases younger than 40,40 to 49,50 to 59 , and aged 60 and older. The variable 105 "method of detection" and "age" was included in these models. The null hypothesis was that 106 there would be no significant difference between variables. A significance level of 0.05 was used 107 for two-tailed $\mathrm{P}$ values.

$108 \quad 2.5$ Techniques of dealing with missing data

109 To maximize the likelihood of comparability and equivalence, four methods were used to 110 deal with missing data based on a missing-at-random assumption. These were as follows: (A)

111 multiple imputation by chained equation (five times) (by R Project, version 3.3.2) [19, 20], with 112 age group, $\mathrm{T}$ stage, $\mathrm{N}$ stage, histologic grade and detection modes included into multivariate 113 regression model; (B) complete randomized imputation (five times), stratified by year [21]; (C) 
114 arbitrarily replacing all missing values for the detection methods into the self-detected mode and

115 deleting other missing values in the group; (D) arbitrarily replacing a missing mode of detection

116 into the screen-detected mode and deleting other missing values in the group.

117

118 3. Results

119 3.1 Pathological characteristics of breast cancer patients

120 We identified 1,086, 1,053, and 1,047 female cases from databases in 1995-2000, 2010, and

121 2015, respectively. From these, we excluded 172 women with ductal carcinoma in situ or

122 bilateral breast cancer. The final study therefore included 3,014 cases of invasive breast cancer:

1231,060 in 1995-2000, 946 in 2010, and 1,008 in 2015. The median (range) ages at presentation

124 were $48.0(19-80)$ years in 1995-2000, $51.0(22-82)$ years in 2010, and 52.0 (18-82) years in

125 2015. The general pathological characteristics of the cancers, including $\mathrm{T}$ stage, $\mathrm{N}$ stage, and

126 histologic grade, are shown in Table 1 for each period.

127 3.2 Pathological differences between the self-detected and screen-detected groups

128 The screen-detected group had a higher proportion of stage T1 tumors than the self-detected 129 group in each database $(75.0 \%$ vs $17.1 \%, \mathrm{P}=0.109$ in $1995-2000 ; 66.7 \%$ vs $40.4 \%, \mathrm{P}<0.001$ in 130 2010; and 67.8\% vs 35.7\%, $\mathrm{P}<0.001$ in 2015) (Table 2 and Fig. 1 -a). The proportion with 131 negative lymph nodes (N0) was also slightly higher in the screen-detected group than in the self132 detected group in each database $(50.0 \%$ vs $47.4 \%, 67.3 \%$ vs $48.4 \%$, and $55.2 \%$ vs $48.5 \%$ in 133 1995-2000, 2010, and 2015, respectively), although statistical significance was only reached for $1342010(\mathrm{P}=0.007)$ (Table 2 and Fig.1-b). The percentages of histologic grade I tumors were 135 significant higher in screen-detected group than that in self-detected group $(22.9 \%$ vs $13.9 \%, \mathrm{P}=$ 1360.017 in 2010) (Table 2 and Fig.1-c). The age distribution showed no significant difference 137 between self-detected and screen-detected group (Table 2 and Fig.2). After adjusting for age, 
138 self-detected group had increased T2 stage cases in $2010(\mathrm{~T} 2 \mathrm{vs} \mathrm{T} 1, \mathrm{OR}=2.817, \mathrm{P}=0.001)$ and

1392015 (T2 vs T1, OR = 3.820, P < 0.001), increased N2-3 stage cases in 2010 (N2-3 vs N0, OR

$140=2.775, \mathrm{P}=0.017$ ) and increased histologic grade III in 2010 (grade III vs $\mathrm{I}, \mathrm{OR}=5.763, \mathrm{P}=$

141 0.026) significantly, compared with screen-detected group (Table 3).

142

143 4. Discussion

144 In this study, we retrospectively compared the differences in pathological characteristics

145 between self-detected and screen-detected breast cancer. The proportion of cases identified by

146 the screening program increased significantly before the introduction of screening. The screen-

147 detected group had smaller tumor sizes and tended to have less lymph node involvement and

148 lower histologic grades compared with the self-detected group.

149 The coverage of the breast cancer screening remains low in Chinese population. From 2009

150 to 2011, a breast cancer screening program, which was launched by the Chinese Anti-Cancer

151 Association with the permission of the Chinese government, only covered 1.46 million women

152 and only 631 with breast cancer [5]. As of 2014, the total number of screened women had risen

153 to 48.35 million, but this still accounts for less than $5 \%$ of the population. Another possible

154 explanation for the low percentage of screen-detected cancer may relate to the theory and

155 technology underpinning existing screening programs and guidelines, typically relying on a lack

156 of indigenous studies. Moreover, the Chinese guidelines for breast cancer screening were not

157 published by the Chinese Anti-Cancer Association, Committee of Breast Cancer Society until

1582007 [22] and have been updated four times over the last decade. These guidelines recommend

159 that women at average risk of breast cancer only undergo opportunistic screening mammography.

160 However, ultrasound and parallel clinical breast examination are the primary screening tools in 161 second-generation screening programs [5]. 
162 Consistent with the findings of previous studies from Japan, Singapore, Korea, and some

163 Western countries, we confirmed the benefits of screening when seeking to detect breast cancer

164 at an early stage [13-15, 23, 24]. Specifically, we identified the prognostic advantages, based on

165 pathological findings at diagnosis, for asymptomatic patients with screen-detected cancers.

166 Comparable to our results $(66.7 \%-75.0 \%$ vs $17.1 \%-40.4 \%)$, higher proportions of screen-

167 detected patients were reported to have stage T1 cancer compared with self-detected groups in 168 studies in both Korea (59.2\% vs 31.7\%) [14] and Hong Kong (44.7\% vs 33.4\%) [16]. A study in

169 Singapore also indicated that screening was an independent factor for better clinical staging at 170 presentation, after adjusting for race and menopausal status [12]. However, although there were

171 trends, we did not find any statistically significant difference for lymph node status or histologic

172 grade between the groups in this study. Mammography was not popular yet as the modality of

173 breast cancer screening in China $[5,10]$. Breast cancer examination was used in most of the

174 screening program which might limit the performance of screening and results unsatisfied tumor 175 stage.

176 In this study, long-term information of 3,014 breast cancer patients from Tianjin Medical

177 University Cancer Institute and Hospital were collected. Because the breast cancer patients at our

178 hospital came from all over the country of China, this database represent a trend of Chinese

179 breast cancer. However, this study has two main limitations. The first is that it was retrospective 180 and that approximately $12 \%$ of values were missing in the detection mode due to the use of 181 electronic documentation. Hence, four imputation methods were used to ascertain whether major 182 differences occurred on the comparison of pathological characteristics between self-detected and 183 screen-detected breast cancer. When using multiple imputation by chained equations, the missing 184 values were completed depending on the interdependency between values [19]. In this regard, 
185 more preferable results tended to be classified into the screen-detected group. When using completely randomized imputation stratified by year, no tendency was seen in either direction.

187 When the missing detection mode values were replaced by "self-detected," the pathological 188 advantage of the screen-detected group was attributed to the self-detected group. The differences

189 between the two groups may therefore have been underestimated. When the missing detection 190 mode values were replaced by "screen-detected," the disadvantage in the self-detected group was 191 attributed to the screen-detected group, also potentially leading to an underestimation of the 192 differences between the two groups. The second limitation is that there was no information about 193 the follow-up or survival status of the patients, for which further studies would be required. A 194 study from the UK reported that the impact of introducing such a screening program on survival 195 was small but significant, and that most of the improved survival was due to a shift in the 196 Nottingham Prognostic Index (used to determine prognosis following surgery for breast cancer) 197 [25]. Similar shifts in pathologic characteristics of prognosis were identified both in this 198 retrospective investigation and in previous studies [26].

\section{5. Conclusion}

201 This study indicates that the breast cancers detected by screening had more favorable 202 clinicopathologic characteristics than those detected by themselves. We also found fewer patients 203 were detected by screening in this study compared with those in Western and Asian developed 204 countries.

\section{Acknowledgments}

206 We thank Dr Robert Sykes (www.doctored.org.uk) for providing editorial services. 


\section{References}

210 [1] Li T, Mello-Thoms C, Brennan PC. 2016. Descriptive epidemiology of breast cancer in

211 China: incidence, mortality, survival and prevalence. Breast cancer research and treatment 212 159(3):395-406.

213 [2] Yang L, Parkin DM, Ferlay J, Li L, Chen Y. 2005. Estimates of cancer incidence in China for 2142000 and projections for 2005. Cancer epidemiology, biomarkers \& prevention 14(1):243-50.

215 [3] Anderson BO, Yip CH, Smith RA, Shyyan R, Sener SF, Eniu A, Carlson RW, Azavedo E, 216 Harford J. 2008. Guideline implementation for breast healthcare in low-income and middle217 income countries: overview of the Breast Health Global Initiative Global Summit 2007. Cancer 218 113(8 Suppl): 2221-43.

219 [4] P. Porter. 2008. "Westernizing" women's risks? Breast cancer in lower-income countries. 220 New England Journal of Medicine 358(3):213-6.

221 [5] Song QK, Wang XL, Zhou XN, Yang HB, Li YC, Wu JP, Ren J, Lyerly HK. 2015. Breast 222 cancer challenges and screening in China: Lessons from current registry data and population 223 screening studies. The oncologist 20(7):773-9.

224 [6] Tabar L, Vitak B, Chen HH, Yen MF, Duffy SW, Smith RA. 2001. Beyond randomized 225 controlled trials: organized mammographic screening substantially reduces breast carcinoma 226 mortality. Cancer 91(9):1724-31.

227 [7] Duffy SW, Tabar L, Chen HH, Holmqvist M, Yen MF, Abdsalah S, Epstein B, Frodis E, 228 Ljungberg E, Hedborg-Melander C, Sundbom A, Tholin M, Wiege M, Akerlund A, Wu HM, 229 Tung TS, Chiu YH, Chiu CP, Huang CC, Smith RA, Rosen M, Stenbeck M, Holmberg L. 2002.

230 The impact of organized mammography service screening on breast carcinoma mortality in 231 seven Swedish counties. Cancer 95(3):458-69.

232 [8] de Gelder R, Heijnsdijk EAM, Fracheboud J, Draisma G, de Koning HJ. 2015. The effects of 233 population-based mammography screening starting between age 40 and 50 in the presence of 234 adjuvant systemic therapy. International Journal of Cancer 137(1):165-172.

235 [9] Sankatsing VDV, van Ravesteyn NT, Heijnsdijk EAM, Looman CWN, van Luijt PA, 236 Fracheboud J, den Heeten GJ, Broeders MJM, de Koning HJ. 2017. The effect of population237 based mammography screening in Dutch municipalities on breast cancer mortality: 20 years of 238 follow-up. International Journal of Cancer doi:10.1002/ijc.30754.

239 [10] Chinese Anticancer Association Breast Cancer Society. 2015. Clinical practice guidelines in 
240 breast cancer. China Oncology 25(9):692-754.

241 [11] Zhu J, Chen JG, Chen YS, Zhang YH, Ding LL, Chen TY. Female breast cancer survival in 242 Qidong, China, 1972-2011: a population-based study. BMC cancer 2014;14:318.

243 [12] Wang WV, Tan SM, Chow WL. 2011. The impact of mammographic breast cancer 244 screening in Singapore: a comparison between screen-detected and symptomatic women. Asian 245 Pacific Journal of Cancer Prevention 12(10):2735-40.

246 [13] Joensuu H, Lehtimaki T, Holli K, Elomaa L, Turpeenniemi-Hujanen T, Kataja V, Anttila A, 247 Lundin M, Isola J, Lundin J. 2004. Risk for distant recurrence of breast cancer detected by 248 mammography screening or other methods. JAMA 292(9):1064-73.

249 [14] Kim J, Lee S, Bae S, Choi MY, Lee J, Jung SP, Kim S, Choe JH, Kim JH, Kim JS, Lee JE, 250 Nam SJ, Yang JH. 2012. Comparison between screen-detected and symptomatic breast cancers 251 according to molecular subtypes. Breast Cancer Research and Treatment 131(2):527-40.

252 [15] Crispo A, Barba M, D'Aiuto G, De Laurentiis M, Grimaldi M, Rinaldo M, Caolo G, D'Aiuto 253 M, Capasso I, Esposito E, Amore A, Di Bonito M, Botti G, Montella M. 2013. Molecular 254 profiles of screen detected vs. symptomatic breast cancer and their impact on survival: results 255 from a clinical series. BMC Cancer 13:15.

256 [16] Lau SS, Cheung PS, Wong TT, Ma MK, Kwan WH. 2016. Comparison of clinical and 257 pathological characteristics between screen-detected and self-detected breast cancers: a Hong 258 Kong study. Hong Kong Medical Journal 22(3):202-9.

259 [17] Edge SB, Compton CC. 2010. The American Joint Committee on Cancer: the 7th edition of 260 the AJCC cancer staging manual and the future of TNM. Annals of Surgical Oncology 261 17(6):1471-4.

262 [18] Lakhani SR, Schnitt SJ, Tan PH, van de Vijver MJ. 2012. WHO classification of tumours of 263 the breast. International Agency for Research on Cancer.

264 [19] Zhang Z. 2016. Multiple imputation with multivariate imputation by chained equation 265 (MICE) package. Annals of Translational Medicine 4(2): 30.

266 [20] Eisemann N, Waldmann A, Katalinic A. 2011. Imputation of missing values of tumour stage 267 in population-based cancer registration. BMC Medical Research Methodology 11:129.

268 [21] Pedersen AB, Mikkelsen EM, Cronin-Fenton D, Kristensen NR, Pham TM, Pedersen L, 269 Petersen I. 2017. Missing data and multiple imputation in clinical epidemiological research. 270 Clinical Epidemiology 9:57-166. 
271 [22] Chinese Anticancer Association Breast Cancer Society. 2007. Clinical practice guidelines in 272 breast cancer (Version 2007). China Oncology 17(5):410-428.

273 [23] Inari H, Shimizu S, Suganuma N, Yoshida T, Nakayama H, Yamanaka T, Yamanaka A, 274 Rino Y, Masuda M. 2017. A comparison of clinicopathological characteristics and long-term 275 survival outcomes between symptomatic and screen-detected breast cancer in Japanese women. 276 Breast Cancer (Tokyo, Japan) 24(1):98-103.

277 [24] Chuwa EW, Yeo AW, Koong HN, Wong CY, Yong WS, Tan PH, Ho JT, Wong JS, Ho GH. 278 2009. Early detection of breast cancer through population-based mammographic screening in 279 Asian women: a comparison study between screen-detected and symptomatic breast cancers. The 280 Breast Journal 15(2):133-9.

281 [25] Wishart GC, Greenberg DC, Britton PD, Chou P, Brown CH, Purushotham AD, Duffy SW. 282 2016. Cancer screening barriers and facilitators for under and never screened populations: A 283 mixed methods study. Cancer epidemiology 45:126-134.

284 [26] Zheng S, Bai JQ, Li J, Fan JH, Pang Y, Song QK, Huang R, Yang HJ, Xu F, Lu N, Qiao YL. 285 2012. The pathologic characteristics of breast cancer in China and its shift during 1999-2008: a 286 national-wide multicenter cross-sectional image over 10 years. International Journal of Cancer 287 131(11):2622-31. 


\section{Table $\mathbf{1}$ (on next page)}

Characteristics of the patients with breast cancer in Tianjin Medical University Cancer Institute and Hospital.

aT=tumor size staging, $\mathrm{bN}=$ lymph node staging. 


\begin{tabular}{|c|c|c|c|}
\hline Characteristics & $\begin{array}{c}1995-2000 \\
(n=1,060)\end{array}$ & $\begin{array}{c}2010 \\
(n=946)\end{array}$ & $\begin{array}{c}2015 \\
(\mathrm{n}=1,008)\end{array}$ \\
\hline Median age, years (range) & $48.0(19-80)$ & $51.0(22-82)$ & $52.0(18-82)$ \\
\hline \multicolumn{4}{|l|}{ Detection mode, n (\%) } \\
\hline Self-detected & $1,034(97.5)$ & $712(75.3)$ & $774(76.8)$ \\
\hline Screen-detected & $4(0.4)$ & $60(6.3)$ & $76(7.5)$ \\
\hline Unknown & $22(2.1)$ & $174(18.4)$ & $158(15.7)$ \\
\hline \multicolumn{4}{|l|}{$\mathrm{T}^{\mathrm{a}}, \mathrm{n}(\%)$} \\
\hline $\mathrm{T} 1$ & $168(15.8)$ & $330(34.8)$ & 299 (29.7) \\
\hline $\mathrm{T} 2$ & $633(59.7)$ & $352(37.2)$ & $430(42.6)$ \\
\hline $\mathrm{T} 3$ & $127(12.0)$ & $45(4.8)$ & $46(4.6)$ \\
\hline $\mathrm{T} 4$ & $46(4.3)$ & $13(1.4)$ & $5(0.5)$ \\
\hline Unknown & $86(8.2)$ & $206(21.8)$ & $228(22.6)$ \\
\hline \multicolumn{4}{|l|}{$\mathrm{N}^{\mathrm{b}}, \mathrm{n}(\%)$} \\
\hline N0 & $467(44.1)$ & $390(41.2)$ & $467(46.4)$ \\
\hline N1 & $397(37.5)$ & $184(19.5)$ & $243(24.1)$ \\
\hline $\mathrm{N} 2$ & $112(10.6)$ & $104(11.0)$ & $90(8.9)$ \\
\hline N3 & $4(0.4)$ & $82(8.7)$ & $124(12.3)$ \\
\hline Unknown & $80(7.4)$ & $186(19.6)$ & $84(8.3)$ \\
\hline \multicolumn{4}{|l|}{ Histologic grade, n (\%) } \\
\hline I & $147(13.9)$ & $103(10.9)$ & $56(5.5)$ \\
\hline II & $605(57.1)$ & $495(52.3)$ & $684(67.9)$ \\
\hline III & $241(22.7)$ & $86(9.1)$ & $102(10.1)$ \\
\hline Unknown & $67(6.3)$ & $262(27.7)$ & $166(16.5)$ \\
\hline
\end{tabular}




\section{Table 2 (on next page)}

Comparison of differences in T stage, $\mathrm{N}$ stage, and histologic grade between selfdetected and screen-detected patients.

a There was no data in the current group. $\mathrm{b}$ The $\mathrm{P}$ value was calculated by Fisher's exact test because the number of patients in the current group was less than 5 . 


\begin{tabular}{|c|c|c|c|c|c|c|c|}
\hline \multicolumn{2}{|c|}{ Characteristics } & \multicolumn{2}{|c|}{ 1995-2000 } & \multicolumn{2}{|c|}{2010} & \multicolumn{2}{|c|}{2015} \\
\hline & & $\begin{array}{c}\text { Self- } \\
\text { detected }\end{array}$ & $\begin{array}{l}\text { Screen- } \\
\text { detected }\end{array}$ & $\begin{array}{c}\text { Self- } \\
\text { detected }\end{array}$ & $\begin{array}{l}\text { Screen- } \\
\text { detected }\end{array}$ & $\begin{array}{c}\text { Self- } \\
\text { detected }\end{array}$ & $\begin{array}{l}\text { Screen- } \\
\text { detected }\end{array}$ \\
\hline \multirow[t]{3}{*}{ T stage, n (\%) } & $\mathrm{T} 1$ & $163(17.1)$ & $3(75.0)$ & $231(40.4)$ & $34(66.7)$ & $219(35.7)$ & $40(67.8)$ \\
\hline & $\mathrm{T} 2$ & $620(65.0)$ & $--^{\mathrm{a}}$ & $289(50.5)$ & $15(29.4)$ & $350(57.1)$ & $17(28.8)$ \\
\hline & $\mathrm{T} 3-4$ & 173 (17.9) & $1(25.0)$ & $52(9.1)$ & $2(3.9)$ & $44(7.2)$ & $2(3.4)$ \\
\hline \multicolumn{2}{|c|}{ Mann-Whitney $U$} & & 1113.000 & & 10651.500 & & 12256.000 \\
\hline \multicolumn{2}{|l|}{$P$} & & $0.109^{b}$ & & $<0.001$ & & $<0.001$ \\
\hline \multirow[t]{3}{*}{ N stage, n (\%) } & No & 455 (47.4) & $2(50.0)$ & $284(48.4)$ & $35(67.3)$ & $347(48.5)$ & $37(55.2)$ \\
\hline & N1 & $389(40.6)$ & $2(50.0)$ & $148(25.2)$ & $10(19.2)$ & $199(27.8)$ & $16(23.9)$ \\
\hline & $\mathrm{N} 2-3$ & $115(12.0)$ & $--^{\mathrm{a}}$ & $155(26.4)$ & $7(13.5)$ & $170(23.7)$ & $14(20.9)$ \\
\hline \multicolumn{2}{|c|}{ Mann-Whitney $U$} & & 1754.000 & & 12116.500 & & 22349.000 \\
\hline \multicolumn{2}{|l|}{$P$} & & $0.868^{b}$ & & 0.007 & & 0.325 \\
\hline \multirow[t]{3}{*}{$\begin{array}{l}\text { Histologic } \\
\text { grade, n (\%) }\end{array}$} & I & $143(14.7)$ & $3(75.0)$ & $72(13.9)$ & $11(22.9)$ & $38(5.9)$ & $3(4.6)$ \\
\hline & II & $591(60.8)$ & $--^{\mathrm{a}}$ & $372(71.8)$ & $35(72.9)$ & 527 (81.6) & $57(87.7)$ \\
\hline & III & $238(24.5)$ & $1(25.0)$ & $74(14.3)$ & $2(4.2)$ & $81(12.5)$ & $5(7.7)$ \\
\hline \multicolumn{2}{|c|}{ Mann-Whitney $U$} & & 1067.500 & & 10388.000 & & 20270.000 \\
\hline \multicolumn{2}{|l|}{$P$} & & $0.100^{\mathrm{b}}$ & & 0.017 & & 0.491 \\
\hline \multirow[t]{4}{*}{ Age } & $<40$ & $138(13.3)$ & $2(50.0)$ & $87(12.2)$ & $3(5.0)$ & $78(10.1)$ & $3(3.9)$ \\
\hline & $40-$ & 428 (41.4) & $--^{\mathrm{a}}$ & $218(30.6)$ & $28(46.7)$ & $233(30.1)$ & $24(31.6)$ \\
\hline & $50-$ & $259(25.0)$ & $2(50.0)$ & $257(36.1)$ & $20(33.3)$ & $390(37.5)$ & $27(35.6)$ \\
\hline & $60-$ & $209(20.2)$ & $--^{\mathrm{a}}$ & $150(21.1)$ & $9(15.0)$ & $173(22.4)$ & $22(28.9)$ \\
\hline \multicolumn{2}{|c|}{ Mann-Whitney $U$} & & 1529.000 & & 20021.500 & & 26602.000 \\
\hline \multicolumn{2}{|l|}{$P$} & & $0.400^{\mathrm{b}}$ & & 0.398 & & 0.149 \\
\hline
\end{tabular}




\section{Table 3(on next page)}

Relationship between pathological characteristics and method of detection of breast cancer patients after adjusting for age.

a $\mathrm{OR}=$ odds ratio values. The $\mathrm{OR}$ value and $\mathrm{P}$ value was calculated by using multinomial logistic regression model after adjusting for age. b There was no data in the current group. $c$ $P$ value indicates statistical significance at the 0.05 level. 


\begin{tabular}{|c|c|c|c|c|c|c|c|c|c|c|}
\hline \multirow{2}{*}{\multicolumn{2}{|c|}{ Characteristics }} & \multicolumn{3}{|c|}{ 1995-2000 } & \multicolumn{3}{|c|}{2010} & \multicolumn{3}{|c|}{2015} \\
\hline & & $O R^{a}$ & $95 \% C I$ & $P$ & $O R^{a}$ & $95 \% C I$ & $P$ & $O R^{a}$ & $95 \% C I$ & $P$ \\
\hline \multirow[t]{2}{*}{ T stage } & $\mathrm{T} 2$ vs $\mathrm{T} 1$ & $--{ }^{b}$ & $---b$ & $--^{b}$ & 2.817 & $1.497-5.300$ & $0.001^{\mathrm{c}}$ & 3.820 & $2.111-6.915$ & $<0.001^{\mathrm{C}}$ \\
\hline & T3-4 vs T1 & 2.961 & $\begin{array}{l}0.303- \\
28.926\end{array}$ & 0.351 & 0.023 & $\begin{array}{c}0.888- \\
16.397\end{array}$ & 0.072 & 3.835 & $\begin{array}{l}0.891- \\
16.498\end{array}$ & 0.071 \\
\hline \multirow[t]{2}{*}{ N stage } & N1 vs N0 & 0.851 & $0.119-6.078$ & 0.872 & 1.832 & $0.882-3.806$ & 0.105 & 1.339 & $0.726-2.469$ & 0.351 \\
\hline & N2-3 vs N0 & $---b$ & $---b$ & $---b$ & 2.775 & $1.203-6.400$ & $0.017^{\mathrm{c}}$ & 1.308 & $0.688-2.486$ & 0.413 \\
\hline \multirow[t]{2}{*}{ Histologic grade } & II vs I & $--\mathrm{b}$ & $--\mathrm{b}$ & $--{ }^{b}$ & 1.636 & $0.793-3.375$ & 0.182 & 0.725 & $0.217-2.424$ & 0.601 \\
\hline & III vs I & 4.544 & $\begin{array}{l}0.463- \\
44.572\end{array}$ & 0.194 & 5.763 & $\begin{array}{l}1.233- \\
26.945\end{array}$ & $0.026^{\mathrm{c}}$ & 1.251 & $0.284-5.517$ & 0.767 \\
\hline
\end{tabular}




\section{Figure 1 (on next page)}

Comparison of the difference between self-detected and screen-detected breast cancer patients in (a) T stage, (b) N stage, and (c) histologic grade in 1995-2000, 2010, and 2015.

Techniques of dealing with missing data included (R) complete-case analysis; (A1-5) multiple imputation by chained equations; (B1-5) completely randomized imputation; (C) arbitrarily replacing missing mode of detection into self-detected mode and deleting other missing values in the group; (D) arbitrarily replacing all missing detection method values into screendetected mode and deleting other missing values in the group. 
${ }_{\mathrm{R}}^{\text {Methods DofJ }}$

A1 0.081

A2 0.122

A3 $\square 0.083$

A4 0.120

A5

B1 0.081

B2 0.081

B3 - 0.081

B4

B5 0.081

C D 0.081

D 0.221

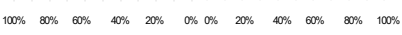
Screen-detected Self-detected a
A1 I I

A2

A3

A4 丩 0.012

A5

B1 10.002

B2 0.003

B3 $\square 0.002$

B4 प 0.001

B5 - 0.001

C 0.001

D 1

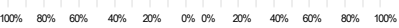
Screen-detected

Self-detected 201

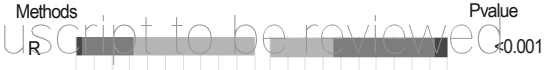

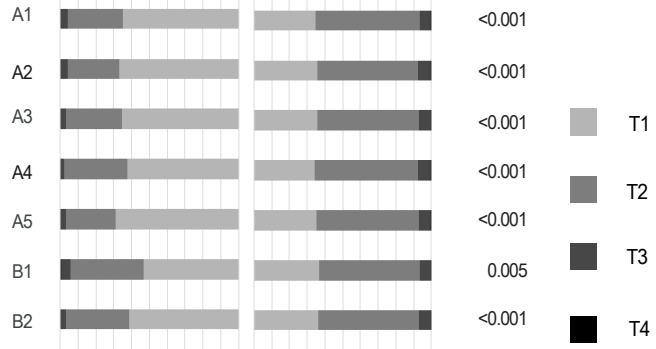

B3 — 0.001

B4 $\quad<0.001$

B5 — $<0.001$

C $\quad<0.001$

D —

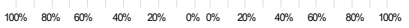
Screen-detected Self-detected

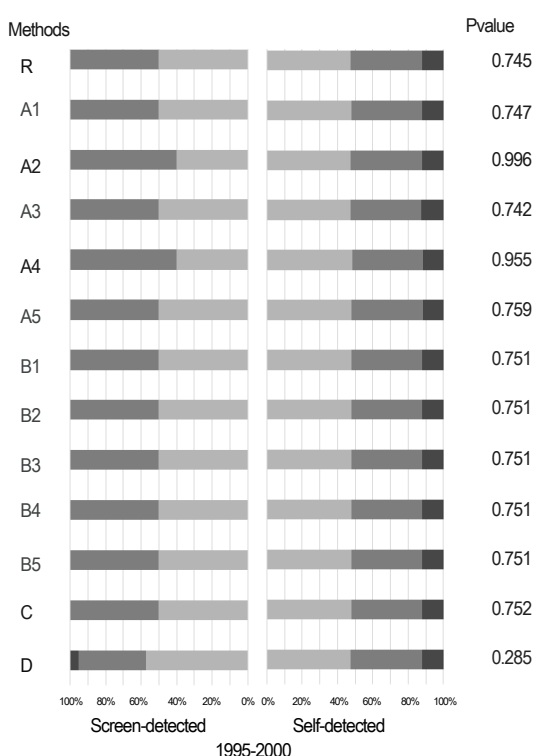

Methods

$\begin{array}{lll}\mathrm{R} & \mathbf{1}\end{array}$

A1 $\quad<0.001$

A2

A3 口 0.009

$\begin{array}{lll}\text { A4 } \square & 0.019\end{array}$

A5 — $\quad<0.001$

$\begin{array}{lll}\text { B1 } & 0.109\end{array}$

B2 $\square-220$

B3 $\square 0.011$

B4 0.031

B5 $\square 0.014$

$\begin{array}{ll}\text { C } & 0.024\end{array}$

D 口 0.004

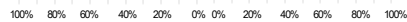
Screen-detected 2010 2015
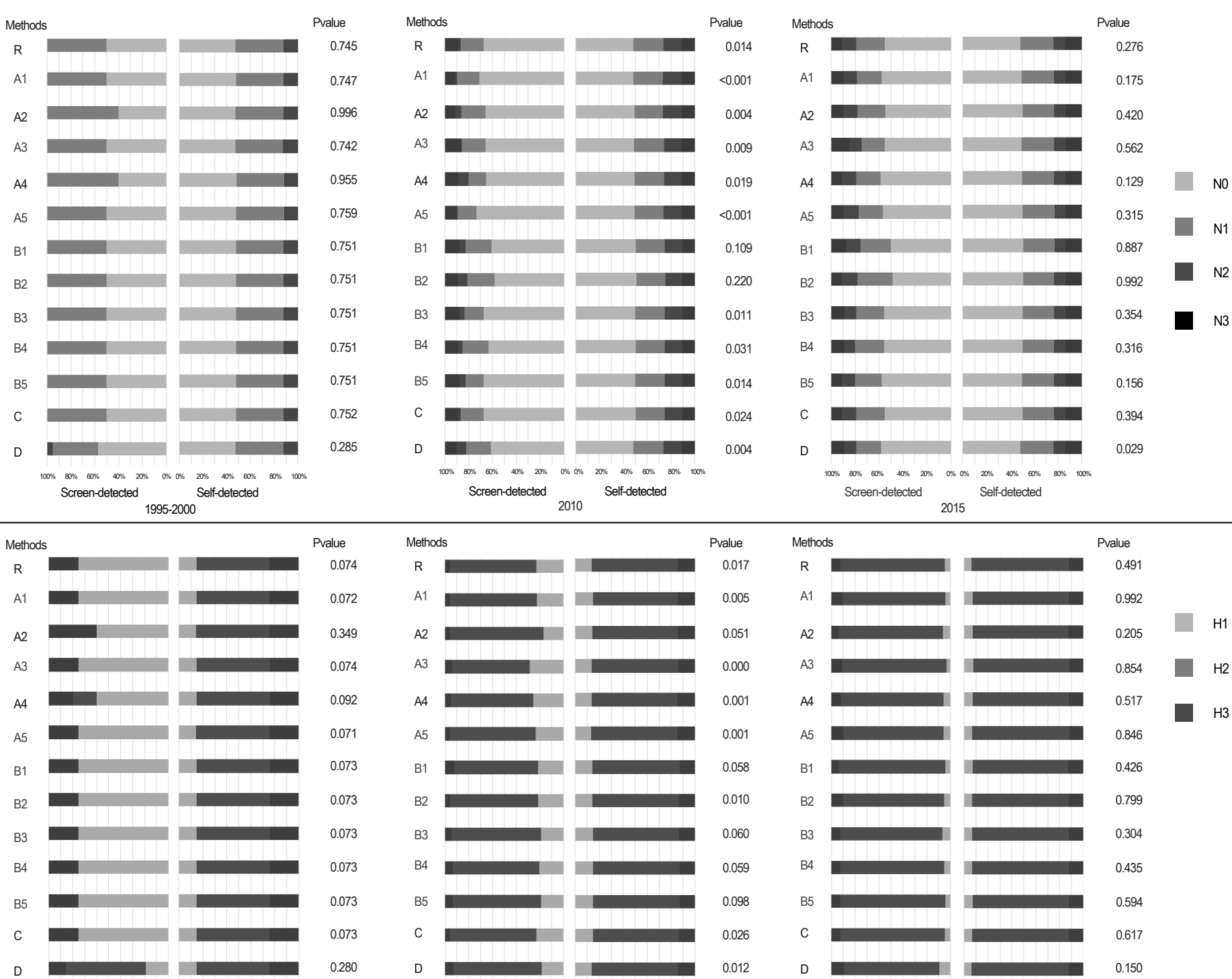

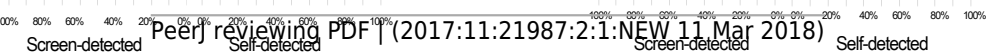
1995-2000

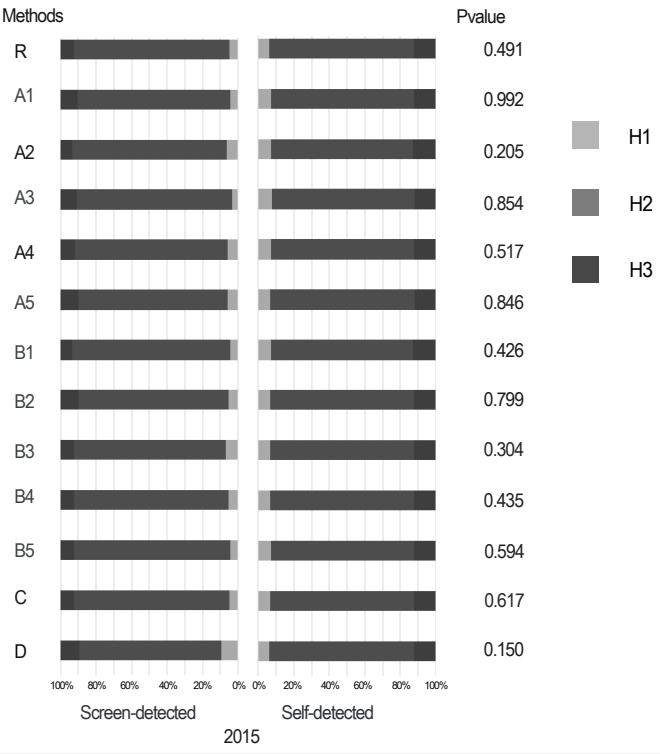




\section{Figure 2 (on next page)}

Frequency distribution at diagnosis, by detection mode in 1995-2000 (95-00), 2010 (10), and 2015 (15).

The age distribution of screen- and self-detected patients was constructed using the 2016 Excel software, while the patients with missing values of detection mode were deleted. Periods of self-detected patients included 1995 to 2000 in full line (Sel.1995-2000), 2010 in dotted dot line (Sel.2010) and 2015 in square dot line (Sel.2015). Periods of screen-detected patients included 1995 to 2000 in dash-dot line (Scr. 1995-2000), 2010 in long dashed line (Sel.2010) and 2015 in short dashed line (Sel.2015). 


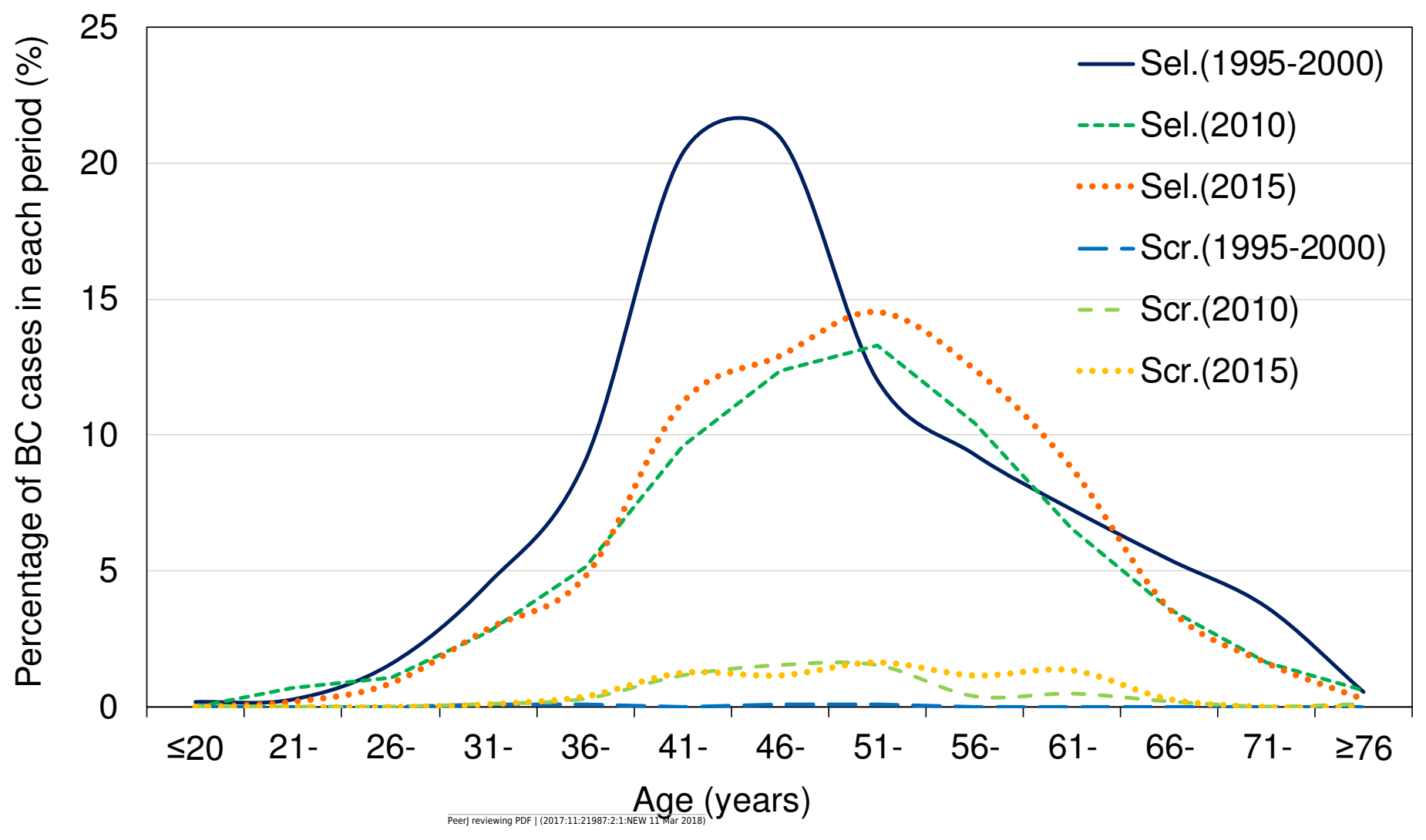

